\title{
Desempenho agronômico e divergência genética entre genótipos de feijão-caupi cultivados no ecótono Cerrado/Pantanal
}

\author{
Jeferson Antônio da Silva Santos; Paulo Eduardo Teodoro (*); Agenor Martinho Correa; \\ Carla Medianeira Giroleta Soares; Larissa Pereira Ribeiro; Hadassa Kathyuci Antunes de Abreu
}

Universidade Estadual de Mato Grosso do Sul (UEMS), Departamento de Produção e Melhoramento Vegetal, Rodovia Aquidauana, km 12, 79200-000 Aquidauana (MS), Brasil.

(*) Autor correspondente: eduteodoro@hotmail.com

Recebido: 8/ago./2014; Aceito: 18/ago./2014

\begin{abstract}
Resumo
Objetivou-se com este trabalho avaliar o desempenho agronômico e a divergência genética entre genótipos de feijão-caupi cultivados na região do ecótono Cerrado/Pantanal. O experimento foi conduzido no ano de 2008 na área experimental da Universidade Estadual de Mato Grosso do Sul, Unidade Universitária de Aquidauana (UEMS/UUA). Os tratamentos consistiram de 20 genótipos de feijão-caupi dispostos em delineamento de blocos casualizados com quatro repetições. Avaliaram-se os seguintes caracteres: início do florescimento, início de maturação, massa de cinco vagens, massa de grãos de cinco vagens, índice de grãos, massa de 100 grãos e produtividade de grãos. A divergência genética entre os tratamentos foi determinada com base na análise de agrupamento e nas variáveis canônicas. O genótipo BRS 17-Gurgueia apresentou maior produtividade de grãos. Híbridos com maior efeito heterótico serão obtidos do cruzamento entre a linhagem Pingo-de-ouro-2 com as cultivares BRS 17-Gurgueia e BRS-Paraguassu.
\end{abstract}

Palavras-chave: caracteres agronômicos, dissimilaridade, variabilidade genética, Vigna unguiculata.

\section{Agronomic performance and genetic divergence among cowpea genotypes in Cerrado/ Pantanal ecotone}

\begin{abstract}
The objective of this study was to evaluate the agronomic performance and genetic divergence among genotypes of cowpea in the Cerrado/Pantanal ecotone region. The experiment was conducted in 2008 in the experimental area of the State University of Mato Grosso do Sul, University Unit of Aquidauana (UEMS/UUA). Treatments consisted of 20 genotypes of cowpea arranged in a randomized complete block design with four replications. Was evaluated the following characters: beginning of the flowering, beginning of the maturation, mass of five pods, grain mass of five pods, grain index, mass of 100 grains and grain yield. The genetic divergence between treatments was determined based on the clustering analysis and the canonical variables. The genotype BRS-17 Gurguéia showed higher grain yield. Hybrids with high heterotic effect will be obtained from crosses of Pingode-ouro-2 strain with BRS 17-Gurguéia and BRS-Paraguassu cultivars.
\end{abstract}

Key words: agronomic characters, dissimilarity, genetic variability, Vigna unguiculata.

\section{INTRODUÇÃO}

O feijão caupi-caupi [Vigna unguiculata (L.) Walp.] é uma das fontes alimentares mais importantes e estratégicas para as regióes tropicais e subtropicais do planeta. Atualmente representa cerca de $15 \%$ da produção de feijão no Brasil. É cultivado, sobretudo, nas regiôes Norte (55,8 mil hectares) e Nordeste (1,2 milhão de hectares) e se constitui no prato básico das classes de menor poder aquisitivo (Teófilo et al., 2008).
Segundo Leite et al. (2009), apesar de ser considerada uma cultura tropical com ampla adaptação aos mais diversos ambientes, o feijão-caupi ainda apresenta baixos patamares de produtividade (em torno de $300 \mathrm{~kg} \mathrm{ha}^{-1}$ ), havendo indícios de que seu potencial genético ultrapassa $6 \mathrm{t} \mathrm{ha}^{-1}$ (Ehlers e Hall, 1997; Freire Filho et al., 2005). Conforme Hall (2004), não há informações suficientes sobre os componentes morfológicos, fisiológicos e genéticos 
relacionados à produtividade e necessários para desenvolver um genótipo altamente produtivo.

Devido à importância que a cultura assume no país, especialmente na região Nordeste, é necessário que estudos sejam feitos para avaliar a divergência genética, visando à seleção de genótipos mais divergentes e de maior potencial produtivo para futuros trabalhos de melhoramento. A avaliação da diversidade genética das populaçóes permite o conhecimento das melhores combinaçôes híbridas, viabilizando a obtenção de genótipos superiores nas gerações segregantes (Passos et al., 2007) e, por conseguinte, auxiliando o melhorista na seleção de combinações mais promissoras e favoráveis aos cruzamentos (Falconer, 1989). Face ao exposto, o objetivo deste trabalho foi avaliar o desempenho agronômico e a divergência genética entre 20 genótipos de feijão-caupi na região do ecótono Cerrado/Pantanal.

\section{MATERIAL E MÉTODOS}

O experimento foi conduzido no município de Aquidauana, MS, regiáo pertencente à zona de transição entre o Cerrado e o Pantanal, coordenadas geográficas $20^{\circ} 20^{\prime} \mathrm{S}$ e $55^{\circ} 48^{\prime} \mathrm{W}$, em uma altitude de 207 metros.

O clima da região, segundo a classificação descrita por Köppen-Geiger, é do tipo Aw (Tropical de Savana), com precipitação média anual de $1.200 \mathrm{~mm}$ e temperaturas máximas e mínimas de $33^{\circ} \mathrm{C}$ e $19{ }^{\circ} \mathrm{C}$, respectivamente. $\mathrm{O}$ solo da área foi classificado por Schiavo et al. (2010) como Argissolo Vermelho-Amarelo distrófico de textura arenosa, cujas características químicas estáo descritas na tabela 1.

O delineamento experimental utilizado foi o de blocos casualizados com quatro repetiçóes. A unidade experimental constou de quatro fileiras de plantas com 5,0 m de comprimento, espaçadas $0,80 \mathrm{~m}$ entre si, considerando-se como área útil apenas as duas linhas centrais de cada parcela, onde se processaram as avaliaçóes.

Os tratamentos consistiram de 20 genótipos de feijãocaupi, constituídos pelas linhagens MNC99-510F-16-1, MNC99-510F-16-3, MNC99-537F-14-2, MNCO1611F-11, MNCO1-614F-15, MNCO1-631F-11, MNCO1631F-15, MNCO1-631F-20-5 e MNCO1-649E-2 e pelos cultivares comerciais Canapuzinho, Canapuzinho-2, Inhuma, Pingo-de-ouro-1-2, Pingo-de-ouro-2, Paulistinha, Patativa, BRS-Paraguassu, BRS-Milênio, BRS 17-Gurgueia e BRS-Marataoã. Todos os genótipos são de porte prostrado ou semiprostrado, provenientes da Embrapa Meio-Norte, Teresina, PI.
O preparo da área constou de duas gradagens pesadas seguidas de duas gradagens niveladoras. A semeadura foi realizada manualmente no dia 18/4/2008 em sulcos abertos mecanicamente, com $5 \mathrm{~cm}$ de profundidade e a uma densidade de semeadura de 16 sementes por metro. O adubo químico, de fórmula 4-20-20, foi distribuído de forma manual e incorporado ao solo dos sulcos a uma dose correspondente a $300 \mathrm{~kg} \mathrm{ha}^{-1}$.

Aos sete dias após a emergência (DAE) foi realizado o desbaste das plântulas, deixando-se oito plântulas por metro. Foram feitas capinas manuais a partir dos 15 DAE, as quais minimizaram o efeito competitivo da corda de viola (Ipomoea sp.) e beldroega (Beldroega sp.), principais espécies infestantes no local do ensaio.

Realizou-se adubação nitrogenada em cobertura em linha no estádio V3 com $60 \mathrm{~kg} \mathrm{ha}^{-1}$ de $\mathrm{N}$, distribuído em filete contínuo, utilizando-se como fonte a ureia. No estádio V4 foi realizado o controle de vaquinhas (Diabrotica speciosa), pulgóes (Aphis craccivora) e cigarrinhas (Empoasca kraemeri) com aplicação do ingrediente ativo Metamidofós, na dose de $600 \mathrm{~g} \mathrm{ha}^{-1}$.

Nas fileiras centrais de cada parcela foram avaliados os seguintes caracteres: início do florescimento (FL), início de maturação (MT), massa de cinco vagens (MCV), massa de grãos de cinco vagens (MGV), índice de grãos (IDG), massa de 100 grãos (MCG) e produtividade de grãos (PROD), conforme realizado por Oliveira et al. (2003).

Inicialmente, para verificar a existência de variabilidade entre os genótipos, os dados obtidos foram submetidos à análise de variância pelo teste $\mathrm{F}$ e as médias foram comparadas pelo teste de Scott e Knott (1974) a 5\% de significância.

A divergência genética entre os tratamentos foi determinada por técnicas multivariadas, que se baseiam na análise de agrupamento. Foi utilizado o método hierárquico aglomerativo de Ward (1963), tendo como medidas de dissimilaridade a distância euclidiana (Everitt e Dunn, 1991) e a distância de Mahalanobis (1930). Todas as análises estatísticas foram realizadas com o aplicativo GENES (Cruz, 2013) e seguiram os procedimentos preconizados por Cruz et al. (2004).

\section{RESULTADOS E DISCUSSÃO}

Houve diferenças significativas $(\mathrm{p}<0,01)$ entre os genótipos para os caracteres DM, MCV, MGV, IDG, MCG e PROD, permitindo inferir sobre a existência de variabilidade genética na população (Tabela 2). Resultados similares foram obtidos

Tabela 1. Análise química do solo da área experimental na camada 0-0,20 m

\begin{tabular}{|c|c|c|c|c|c|c|c|c|c|}
\hline $\mathrm{pH}$ & $\mathbf{P}$ & M.O. & $\mathbf{K}$ & $\mathrm{Ca}$ & Mg & Al & $\mathrm{H}+\mathrm{Al}$ & СTC & V \\
\hline & $\mathrm{mg} \mathrm{dm}^{-3}$ & $\mathbf{g ~ k g}^{-1}$ & & ...... & .......C & $-3 \ldots \ldots$ & $\ldots . .$. & & $\%$ \\
\hline 6,1 & 44,4 & 1,4 & 0,25 & 2,0 & 0,3 & 0,1 & 2,7 & 5,25 & 49 \\
\hline
\end{tabular}

pH: CaCl; P: Mehlich. 
Tabela 2. Quadrado médio (QM), coeficiente de variação (CV) e valores médios dos caracteres dias para o florescimento e maturação (DF e DM, respectivamente), massa de cinco vagens, de grãos de cinco vagens e de 100 grãos (MCV, MGV e MCG, respectivamente), índice de grãos e produtividade de 20 genótipos de feijão-caupi

\begin{tabular}{|c|c|c|c|c|c|c|c|}
\hline \multirow{2}{*}{ Genótipo } & DF & DM & MCV & MGV & \multirow{2}{*}{$\begin{array}{l}\text { IDG } \\
(\%)\end{array}$} & \multirow{2}{*}{$\begin{array}{c}\text { MCG } \\
\text { (g) }\end{array}$} & \multirow{2}{*}{$\begin{array}{c}\text { PROD } \\
\left(\mathrm{kg} \mathrm{ha}^{-1}\right)\end{array}$} \\
\hline & \multicolumn{2}{|c|}{----- dias ----- } & \multicolumn{2}{|c|}{--------- g --------- } & & & \\
\hline BRS 17-Gurgueia & 50 & $75 \mathrm{~b}$ & $15,4 b$ & $10,2 b$ & $74,1 \mathrm{a}$ & $15,8 \mathrm{c}$ & $2.197 \mathrm{a}$ \\
\hline BRS-Marataoã & 55 & $77 \mathrm{~b}$ & $16,4 \mathrm{~b}$ & $11,4 b$ & $69,7 \mathrm{~b}$ & $21,2 b$ & 579 e \\
\hline BRS-Milênio & 50 & $80 \mathrm{a}$ & $16,4 \mathrm{~b}$ & $12,8 \mathrm{~b}$ & $73,1 \mathrm{a}$ & $22,9 \mathrm{~b}$ & $118 \mathrm{f}$ \\
\hline BRS-Paraguassu & 49 & $75 b$ & $19,5 \mathrm{a}$ & $13,9 \mathrm{a}$ & $75,1 \mathrm{a}$ & $21,5 \mathrm{~b}$ & $1.515 b$ \\
\hline Canapuzinho & 49 & $76 b$ & $21,5 \mathrm{a}$ & $15,8 \mathrm{a}$ & $73,7 \mathrm{a}$ & $23,4 \mathrm{a}$ & $738 d$ \\
\hline Canapuzinho-2 & 51 & $75 b$ & $23,3 \mathrm{a}$ & $17,3 \mathrm{a}$ & $74,1 \mathrm{a}$ & $24,0 \mathrm{a}$ & $713 d$ \\
\hline Inhuma & 49 & $75 b$ & $22,6 \mathrm{a}$ & $16,7 \mathrm{a}$ & $73,8 \mathrm{a}$ & $24,3 \mathrm{a}$ & $897 c$ \\
\hline MNC01-631F-11 & 50 & $80 \mathrm{a}$ & $17,8 \mathrm{~b}$ & $11,3 \mathrm{~b}$ & $63,3 b$ & $19,6 \mathrm{~b}$ & $164 j$ \\
\hline MNC99-510F-16-1 & 52 & $76 b$ & $19,0 \mathrm{~b}$ & $13,2 b$ & $69,8 \mathrm{~b}$ & $23,2 \mathrm{a}$ & $1.180 \mathrm{~b}$ \\
\hline MNC99-510F-16-3 & 52 & $78 \mathrm{a}$ & $17,1 \mathrm{~b}$ & $12,2 \mathrm{~b}$ & $71,4 \mathrm{a}$ & $19,3 \mathrm{~b}$ & $668 \mathrm{~d}$ \\
\hline MNC99-537F-14-2 & 47 & $75 b$ & $16,9 \mathrm{~b}$ & $12,1 \mathrm{~b}$ & $71,4 \mathrm{a}$ & $22,6 b$ & $903 c$ \\
\hline MNCO1-611F-11 & 51 & $77 \mathrm{~b}$ & $16,6 \mathrm{~b}$ & $11,9 \mathrm{~b}$ & $71,8 \mathrm{a}$ & $19,5 \mathrm{~b}$ & $865 c$ \\
\hline MNCO1-614F-15 & 52 & $78 \mathrm{a}$ & $16,6 \mathrm{~b}$ & $11,9 \mathrm{~b}$ & $71,4 \mathrm{a}$ & $19,8 \mathrm{~b}$ & 367 e \\
\hline MNCO1-631F-11 & 52 & $77 \mathrm{~b}$ & $19,4 \mathrm{a}$ & $13,8 \mathrm{a}$ & $71,2 \mathrm{a}$ & $21,9 \mathrm{~b}$ & $400 \mathrm{e}$ \\
\hline MNCO1-631F-15 & 50 & $76 \mathrm{~b}$ & $18,3 \mathrm{~b}$ & $12,7 \mathrm{~b}$ & $69,3 \mathrm{~b}$ & $22,0 \mathrm{~b}$ & $295 f$ \\
\hline MNCO1-649E-2 & 50 & $77 \mathrm{~b}$ & $19,5 \mathrm{a}$ & $13,9 a$ & $71,4 \mathrm{a}$ & $21,4 \mathrm{~b}$ & $698 d$ \\
\hline Patativa & 48 & $75 b$ & $21,7 \mathrm{a}$ & $15,4 \mathrm{a}$ & $70,8 \mathrm{a}$ & $24,0 \mathrm{a}$ & $1.204 b$ \\
\hline Paulistinha & 51 & $76 b$ & $22,5 \mathrm{a}$ & $15,8 \mathrm{a}$ & $70,1 \mathrm{a}$ & $22,3 \mathrm{~b}$ & $1.180 \mathrm{~b}$ \\
\hline Pingo-de-ouro-1-2 & 49 & $76 b$ & $23,7 \mathrm{a}$ & $17,5 \mathrm{a}$ & $73,5 \mathrm{a}$ & $27,1 \mathrm{a}$ & $953 c$ \\
\hline Pingo-de-ouro-2 & 48 & $75 b$ & $22,2 \mathrm{a}$ & $16,4 \mathrm{a}$ & $74,1 \mathrm{a}$ & $23,4 \mathrm{a}$ & 964 c \\
\hline Média & 50 & 76 & 19,3 & 13,8 & 71,7 & 22,0 & 797 \\
\hline CV \% & 4,74 & 1,64 & 11,21 & 13,03 & 3,73 & 12,26 & 16,50 \\
\hline QM & $8,74^{\text {ns }}$ & $9,73^{*}$ & $28,71^{*}$ & $19,33^{*}$ & $23,75^{*}$ & $27,58^{*}$ & $943014,36^{*}$ \\
\hline
\end{tabular}

em outros trabalhos com feijão-caupi (Barros et al., 2013; Bertini et al., 2009; Cargnelutti Filho et al., 2010; Costa et al., 2013; Lopes et al., 2001; Oliveira et al. 2002; 2003; Santos et al., 2014; Teixeira et al. 2010).

Os genótipos não diferiram entre si quanto aos dias para o florescimento, apresentando média geral de 50 dias. Os genótipos BRS-Milênio, MNC01-631F-11, MNC99510F-16-3 e MNCO1-614F-15 apresentaram o ciclo mais longo. A média geral desse caráter foi de 76 dias, o que de acordo com Craufurd et al. (1997) classifica os genótipos como de ciclo médio-precoce. Ehlers e Hall (1997) relatam que a precocidade é uma importante característica devido ao clima específico de cada região, pois cultivares e linhagens precoces podem escapar de estiagens que frequentemente ocorrem em zonas semiáridas. Isso tem contribuído para aumentar, ou pelo menos estabilizar, a produção de feijáocaupi em períodos longos de estiagem (Cisse et al., 1995; Craufurd et al., 1997).

Os genótipos Pingo-de-ouro-1-2, Pingo-de-ouro-2, Patativa, Inhuma, Canapuzinho-2 e Canapuzinho obtiveram os maiores valores para os caracteres MCV, MGV, IDV e MCG. A obtenção dos valores de MCV e MGV é de interesse para a avaliaçấo das características morfoagrônomicas de um dado genótipo, pois é por meio desses caracteres que se obtem o valor do IDG. Esse caráter é importante nos genótipos destinados à produção de grãos verdes, uma vez que mede a eficiência da cultivar na alocação de fotossintados para os gráos, além de servir como referência para trabalhos de seleção (Craufurd et al., 1997; Freire Filho et al., 2005).

O genótipo BRS 17-Gurgueia apresentou a maior produtividade de grãos, com $2.197 \mathrm{~kg} \mathrm{ha}^{-1}$, o que demonstra, inicialmente, boa adaptação às condiçóes edafoclimáticas da regiáo do ecótono Cerrado/Pantanal. Com exceçáo dos genótipos BRS-Milênio, MNC01-631F-11, MNCO1614F-15, MNCO1-631F-11 e MNCO1-631F-15, os demais apresentaram patamares de produtividade superiores à média nacional para o mesmo período (aproximadamente $370 \mathrm{~kg} \mathrm{ha}^{-1}$. No entanto, a produtividade média de $797 \mathrm{~kg}$ $\mathrm{ha}^{-1}$ foi inferior às médias obtidas por Bezerra et al. (2008), Lopes et al. (2001), Matos Filho (2009) e Teixeira et al. (2010), que foram de 1.007, 1.049, 1.307 e $1.705 \mathrm{~kg} \mathrm{ha}^{-1}$, respectivamente.

O agrupamento de Ward, com base tanto à distância Euclidiana média (Figura 1), quanto à distância de Mahalanobis (Figura 2), alocou os genótipos de feijāocaupi em cinco grupos distintos. Apesar das medidas de dissimilaridade formarem um mesmo número de grupos, houve grandes diferenças na composição deles. Resultados semelhantes foram observados por Cargnelutti Filho et al. (2008; 2010), que ao avaliarem a divergência genética entre 


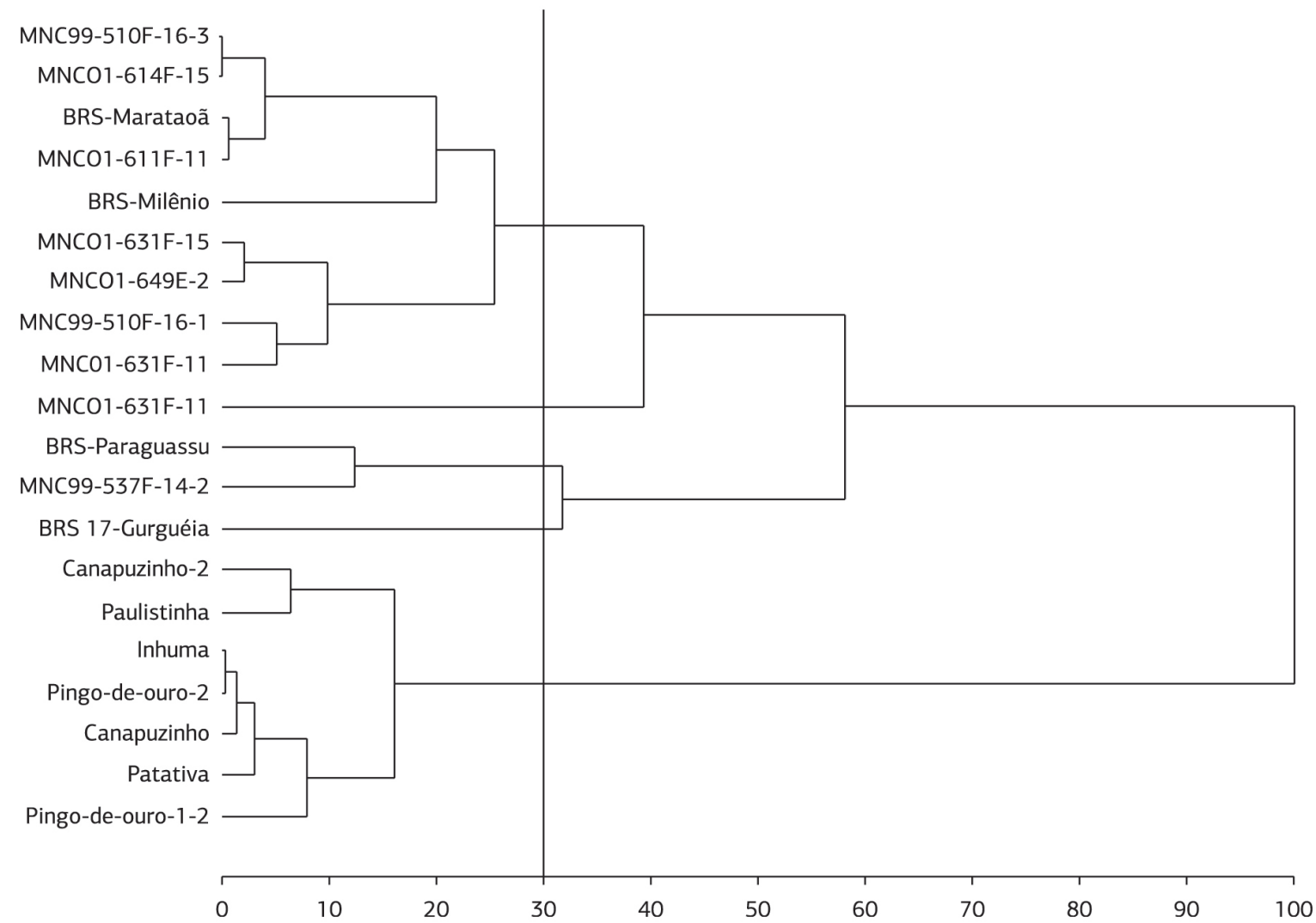

Figura 1. Dendrograma da dissimilaridade genética entre 20 genótipos de feijão-caupi obtidos pelo método de agrupamento de Ward, utilizando a distância Euclidiana média.

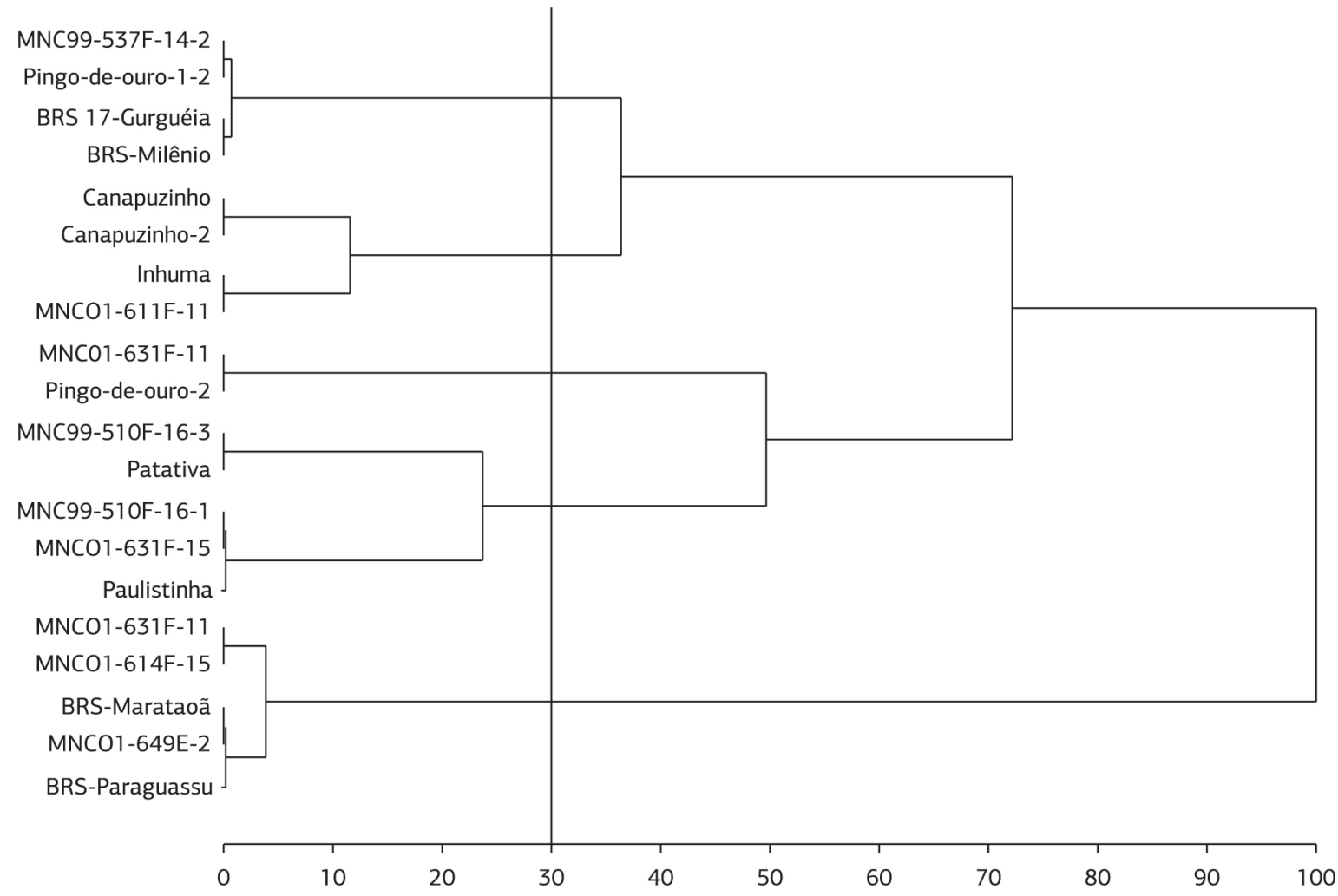

Figura 2. Dendrograma da dissimilaridade genética entre 20 genótipos de feijão-caupi obtidos pelo método de agrupamento de Ward, utilizando a distância Mahalanobis. 
Tabela 3. Contribuição relativa de sete caracteres para divergência genética em 20 genótipos de feijão-caupi, conforme critério de Singh (1981)

\begin{tabular}{|c|c|c|c|c|}
\hline \multirow{2}{*}{ Caráter } & \multicolumn{2}{|c|}{ Distância Euclidiana média } & \multicolumn{2}{|c|}{ Distância de Mahalanobis } \\
\hline & S.j. & S.j. (\%) & S.j. & S.j. (\%) \\
\hline DF & 17153,0 & 0,0 & 484,7 & 4,8 \\
\hline DM & 282,2 & 0,0 & 150,7 & 1,4 \\
\hline MCV & 102598,0 & 0,1 & 599,3 & 6,0 \\
\hline MGV & 1027,5 & 0,0 & 4318,8 & 43,2 \\
\hline IDG & 1831,3 & 0,0 & 510,0 & 5,0 \\
\hline MCG & 102844,2 & 0,2 & 2879,2 & 28,8 \\
\hline PROD & 75090603,4 & 99,8 & 1040,1 & 10,8 \\
\hline
\end{tabular}

genótipos de feijoeiro comum verificaram discordância entre essas medidas.

Cruz et al. (2004) ressaltam que a distância Euclidiana média deve ser utilizada em experimentos que não contemplam repetição, por ser difícil a quantificação da influência do ambiente que atua sobre as constituições genéticas. Essa técnica é recomendada para a avaliação de acessos em bancos de germoplasma, onde o número considerável de genótipos inviabiliza a utilização de delineamento experimental. Entretanto, a distância de Mahalanobis pode ser estimada apenas quando o delineamento experimental contempla repetição, permitindo a quantificação dos efeitos do ambiente sobre as constituiçóes genéticas (Cargnelutti Filho et al., 2010).

Com base na distância Euclidiana média, o par formado entre os genótipos MNC99-510F-16-3 e MNCO1-614F-15 foi o mais próximo, diferindo do obtido pela distância de Mahalanobis, onde os genótipos MNCO1-649E-2 e Pingo-de-ouro-2 constituíram o par mais similar. Tais pares, por apresentarem mesmo padrão de similaridade, não são recomendados para utilização em programas de melhoramento genético por hibridação, para que a variabilidade genética, indispensável em qualquer programa de melhoramento, não seja restrita, de modo a inviabilizar os ganhos a serem obtidos por seleção.

Pela distância Euclidiana média, o par mais divergente foi composto pelos genótipos BRS 17-Gurgueia e Pingo-deouro-1-2, enquanto a distância de Mahalanobis identificou os genótipos BRS-Paraguassu e Pingo-de-ouro-1-2 como mais divergentes. Essa alta divergência, a princípio, permite recomendar o cruzamento entre esses pares, visando a maximizar a heterose nas progênies e a aumentar a possibilidade de ocorrência de segregantes nas geraçóes avançadas (Cruz et al., 2004).

Com base na distância Euclidiana média, o caráter PROD foi o que mais contribui para a divergência entre os 20 genótipos de feijão-caupi (Tabela 3). Esses resultados corroboram os obtidos por Passos et al. (2007), que constataram que o caráter PROD foi o que mais contribui para a divergência genética em genótipos de feijão-caupi. Entretanto, baseado na distância de Mahalanobis, os caracteres MCV e MCG foram mais sensíveis em proporcionar divergência genética entre os genótipos. Esses resultados se assemelham aos obtidos por Bertini et al. (2009) e
Oliveira et al. (2003), que verificaram que os caracteres comprimento de vagem e MCG apresentaram maior contribuição para divergência em genótipos de feijão-caupi. De acordo com Cruz et al. (2004), a diferença observada entre as técnicas é devida à distância Euclidiana média fazer inferências sobre a dissimilaridade fenotípica, enquanto a distância de Mahalanobis quantifica a dissimilaridade genotípica.

\section{CONCLUSÃO}

O genótipo BRS 17-Gurgueia apresentou maior produtividade de grãos. Híbridos com maior efeito heterótico serão obtidos do cruzamento entre a linhagem Pingo-deouro-2 com as cultivares BRS 17-Gurgueia e BRS-Paraguassu.

\section{REFERÊNCIAS}

BARROS, M.A.; ROCHA, M.M.; GOMES, R.L.F.; DAMASCENOSILVA, K.J.; NEVES, AC. Adaptabilidade e estabilidade produtiva de feijão-caupi de porte semiprostrado. Pesquisa Agropecuária Brasileira, v.48, p.403-410, 2013. http://dx.doi.org/10.1590/S0100204X2013000400008

BERTINI, C.H.C.; TEÓFILO, E.M.; DIAS, F.T.C. Divergência genética entre acessos de feijáo-caupi do banco de germoplasma da UFC. Revista Ciência Agronômica, v.40, p.99-105, 2009.

BEZERRA, A.A.C.; TÁVORA, F.J.A.F.; FREIRE FILHO, F.R.; RIBEIRO, V.Q. Morfologia e produção de grãos em linhagens modernas de feijâo-caupi submetidas a diferentes densidades populacionais. Revista de Biologia e Ciências da Terra, v.8, p.85-92, 2008.

CARGNELUTTI FILHO, A.; RIBEIRO, N.D.; BURIN, C. Consistência do padrão de agrupamento de cultivares de feijão conforme medidas de dissimilaridade e métodos de agrupamento. Pesquisa Agropecuária Brasileira, v.45, p.236-243, 2010.

CARGNELUTTI FILHO, A.; RIBEIRO, N.D.; REIS, R.C.P.; SOUZA, J.R.; JOST, E. Comparação de métodos de agrupamento para o estudo da divergência genética em cultivares de feijão. Ciência Rural, v.38, p.2138-2145, 2008. http://dx.doi.org/10.1590/S010384782008000800008 
CISSE, N.; NDIAYE, M.; THIAW, S.; HALL, A.E.E. Registration of "Mouride" cowpea. Crop Science, v.35, p.1215-1216, 1995. http:// dx.doi.org/10.2135/cropsci1995.0011183X003500040068x

COSTA, E.M.R.; DAMASCENO-SILVA, K.J.; ROCHA, M.M.; MEDEIROS, A.M.; ANUNCIAÇÃO-FILHO, C.J. Genetic divergence among African cowpea lines by morphoagronomic traits. Genetics and Molecular Research, v.12, p.6773-6781, 2013. PMid:24391025. http://dx.doi.org/10.4238/2013.December.16.3

CRAUFURD, P.Q.; SUMMEIFIELD, R.J.; ELLIS, R.H.; ROBERTS, E.H. Photoperiod, temperature, and the growth and development of cowpea. In: SINGH, B.B.; MOHAN RAJ, D.R.; DASHIELL, K.E.; JACKAI, L.E.N. (Ed.). Advances in Cowpea Research. Ibadan: International Institute of Tropical Agriculture: Japan International Research Center for Agricultural Sciences, 1997. p.75-86.

CRUZ, C.D. GENES: a software package for analysis in experimental statistics and quantitative genetics. Acta Scientiarum Agronomy, v.35, p.271-276, 2013. http://dx.doi.org/10.4025/actasciagron.v35i3.21251

CRUZ, C.D.; REGAZZI, A.J.; CARNEIRO, P.C.S. Modelos biométricos aplicados ao melhoramento genético. 3.ed. Viçosa: UFV, 2004. 80p.

EHLERS, J.D.; HALL, A.E. Cowpea (Vigna unguiculata L. Walp.). Field Crops Research, v.53, p.187-204, 1997. http://dx.doi.org/10.1016/ S0378-4290(97)00031-2

EVERITT, B.S.; DUNN, G. Applied multivariate analysis. London: Edward Arnold, 1991. 400p.

FALCONER, D.S. Introduction to quantitative genetics. New York: Longman, 1989. 489p.

FREIRE FILHO, F.R.; RIBEIRO, V.Q.; BARRETO, P.D.; SANTOS, A.A. Melhoramento genético. In: FREIRE FILHO, F.R.; LIMA, J.A.A.; RIBEIRO, V.Q. (Ed.). Feijão-caupi: avanços tecnológicos. Brasília: Embrapa Informação Tecnológica, 2005. p.29-92.

HALL, A.E. Breeding for adaptation to drought and heat in cowpea. European Journal of Agronomy, v.21, p.447-454, 2004. http://dx.doi. org/10.1016/j.eja.2004.07.005

LEITE, L.F.C.; ARAÚJO, A.S.F.; COSTA, C.N.; RIBEIRO, A.M.B. Nodulação e produtividade de grãos do feijão-caupi em resposta ao molibdênio. Revista Ciência Agronômica, v.40, p.492-497, 2009.

LOPES, A.C.A.; FREIRE FILHO, F.R.; SILVA, R.B.Q.; CAMPOS, F.L.; ROCHA, M.M. Variabilidade entre caracteres agronômicos em caupi (Vigna unguiculata (L.) Walp.). Pesquisa Agropecuária Brasileira, v.36, p.515-520, 2001. http://dx.doi.org/10.1590/S0100204X2001000300016

MAHALANOBIS, P.C. On the test and measures of group divergence. Journal of Asiatic Society, v.26, p.541-588, 1930.
MATOS FILHO, C.H.A.; GOMES, R.L.F;; ROCHA, M.M.; FREIRE FILHO, F.F.; LOPES, A.C.A. Potencial produtivo de progênies de feijão-caupi com arquitetura ereta de planta. Ciência Rural, v.39, p.348354, 2009. http://dx.doi.org/10.1590/S0103-84782009000200006

OLIVEIRA, F.J.; COSTA, C.N.; RIBEIRO, A.M.B. Caracteres agronômicos aplicados na seleçáo de cultivares de feijão-caupi. Revista Ciência Agronômica, v.34, p.5-11, 2003.

OLIVEIRA, A.P.; SOBRINHO, J.T.; NASCIMENTO, J.T.; ALVES, A.U.; ALBUQUERQUE, I.C.; BRUNO, G.B. Avaliação de linhagens e cultivares de feijâo-caupi, em Areias, PB. Horticultura Brasileira, v.20, p.180-182, 2002. http://dx.doi.org/10.1590/S010205362002000200012

PASSOS, A.R.; SILVA, S.A.; CRUZ, P.J.; ROCHA, M.M.; CRUZ, E.M.O.; ROCHA, M.A.C.; BAHIA, H.F; SALDANHA, R.B. Divergência genética em feijão-caupi. Bragantia, v.66, p.579-586, 2007. http://dx.doi.org/10.1590/S0006-87052007000400007

SANTOS, J.A.S.; SOARES, C.M.G.; CORRÊA, A.M.; TEODORO, P.E.; RIBEIRO, L.P.; ABREU, H.K.A. Agronomic performance and genetic dissimilarity among cowpea (Vigna unguiculata (L.) Walp.) genotypes. Global Advanced Research Journal of Agricultural Science, v.3, p.205-211, 2014.

SCHIAVO, J.A.; PEREIRA, M.G.; MIRANDA, L.P.M.; DIAS NETO, A.H.; FONTANA, A. Caracterização e classificação de solos desenvolvidos de arenitos da formaçáo Aquidauana-MS. Revista Brasileira de Ciência do Solo, v.34, p.881-889, 2010. http://dx.doi. org/10.1590/S0100-06832010000300029

SCOTT, A.; KNOTT, M. Cluster-analysis method for grouping means in analysis of variance. Biometrics, v.30, p.507-512, 1974. http://dx.doi.org/10.2307/2529204

SINGH, D. The relative importance of characters affecting genetic divergence. Indian Journal of Genetic and Plant Breeding, v.41, p.237-245, 1981.

TEÓFILO, E.M.; ALVES, A.U.; ALBUQUERQUE, I.C.; BRUNO, G.B. Potencial fisiológicos de sementes de feijâo caupi produzidas em duas regiôes do estado do Ceará. Revista Ciência Agronômica, v.39, p.443-448, 2008.

TEIXEIRA, I.R.; SILVA, G.C.; OLIVEIRA, J.P.R.; SILVA, A.G.; PELÁ, A. Desempenho agronômico e qualidade de sementes de cultivares de feijão-caupi na regiáo do cerrado. Revista Ciência Agronômica, Fortaleza, v.41, p.300-307, 2010. http://dx.doi.org/10.1590/S180666902010000200019

WARD, J.H. Hierarchical grouping to optimize an objective function. Journal of the American Statistical Association, v.58, p.236-244, 1963. http://dx.doi.org/10.1080/01621459.1963.10500845 